\title{
BMJ Open Traumatic life events and risk of post- traumatic stress disorder among the Indigenous population of regional, remote and metropolitan Central- Eastern Australia: a cross-sectional study
}

\author{
Bushra F Nasir (D) , ${ }^{1}$ Emma Black, ${ }^{1}$ Maree Toombs, ${ }^{1}$ Steve Kisely (D) , ${ }^{2}$ \\ Neeraj Gill (D) , ${ }^{1}$ Gavin Beccaria, ${ }^{3}$ Srinivas Kondalsamy-Chennakesavan, ${ }^{1}$ \\ Geoffrey Nicholson ${ }^{1}$
}

To cite: Nasir BF, Black E, Toombs M, et al. Traumatic life events and risk of posttraumatic stress disorder among the Indigenous population of regional, remote and metropolitan CentralEastern Australia: a crosssectional study. BMJ Open 2021;11:e040875. doi:10.1136/ bmjopen-2020-040875

- Prepublication history and supplemental material for this paper is available online. To view these files, please visit the journal online (http://dx.doi. org/10.1136/bmjopen-2020040875).

Received 26 May 2020 Revised 02 March 2021 Accepted 01 April 2021

Check for updates

(C) Author(s) (or their employer(s)) 2021. Re-use permitted under CC BY-NC. No commercial re-use. See rights and permissions. Published by BMJ.

For numbered affiliations see end of article.

Correspondence to

Dr Bushra F Nasir;

b.nasir@uq.edu.au

\section{ABSTRACT}

Objective Trauma is reported by $70 \%$ of the global population and $4 \%$ of those exposed develop posttraumatic stress disorder (PTSD), but data from Indigenous populations are limited. We aimed to determine the prevalence, types and age of occurrence of traumatic events among community-living Indigenous Australians and associations with PTSD.

Design Lifetime trauma and PTSD were quantified among a broadly representative sample of 544 Indigenous participants using a diagnostic clinical interview. Logistic regression examined predictors of PTSD.

Setting Metropolitan, regional and remote areas of Southern Queensland and Northern New South Wales.

Participants Indigenous Australians 18 years and older. Outcome measures Prevalence of traumatic life events and risk of PTSD.

Results $64.9 \%$ of participants (standardised prevalence $62.6 \%$ ) reported lifetime trauma, with more than one trauma category in $62.3 \%$. Females reported 2.3 times more sexual violence, otherwise no gender differences existed. The prevalence of four common trauma categories were 1.7-3.0 times higher than in the Australian population; physical violence being the highest relative risk. Although overall childhood trauma was not increased, sexual or physical violence before age 15 was twice more common than in the Australian population.

The standardised prevalence of 12-month PTSD was $13.3 \%$ (95\% Cl 10.4 to 16.1$), 16.1 \%(95 \%$ Cl 12.2 to 19.9$)$ in females and $8.2 \%(95 \% \mathrm{Cl} 5.3$ to 11.1$)$ in males, three times the Australian rates. In multiple regression analysis, independent predictors of PTSD were female gender (OR 2.1), rural residence $(O R 3.0)$, trauma under age $10(O R$ $2.2)$, sexual (without physical) violence (OR 2.5), physical (without sexual) violence (OR 2.3), and both sexual and physical violence (OR 5.0).

Conclusion Indigenous Australians are more likely to experience potentially harmful traumas and develop PTSD than other Australians. Mitigation of trauma among Indigenous Australians, particularly childhood exposure and sexual or physical violence, is essential to reduce their high burden of PTSD.

\section{Strengths and limitations of this study}

This is the first study to explore the prevalence of traumas and post-traumatic stress disorder (PTSD) for Indigenous Australians living in metropolitan, regional and remote areas in comparison to other Australians.

- This study identified that Indigenous Australians are more likely to experience traumas and develop PTSD as compared with their non-Indigenous counterparts.

- A significant limitation is that this study was conducted according to Diagnostic and Statistical Manual of Mental Disorders, Fourth Edition (DSM-IVTR) criteria for trauma and PTSD, which have been revised in the next version, Diagnostic and Statistical Manual of Mental Disorders, Fifth Edition (DSM-5).

- The DSM-5 has a revised PTSD construct; lower rates of PTSD have been found in DSM-5.

\section{INTRODUCTION}

Exposure to trauma is highly prevalent worldwide. In an analysis of WHO world mental health surveys from 24 countries $(n=68894)$, $70.4 \%$ of respondents had experienced lifetime traumatic events, with an average of 3.2 trauma types per capita. ${ }^{1}$ The risk of posttraumatic stress disorder (PTSD) as assessed by the Diagnostic and Statistical Manual of Mental Disorders, Fourth Edition/Composite International Diagnostic Interview (DSM-IV/CIDI) after trauma exposure was $4.0 \%$, although there was considerable variation by trauma type. For instance, being raped increased the risk almost fivefold, intimate partner sexual violence or being kidnapped almost threefold, and 'other' (uncoded) and 'private' traumas 2.3-fold. ${ }^{1}$ This paper also reported a high population burden of PTSD due to 
persistence of symptoms with a mean duration of 72.3 months. The most persistent symptoms were associated with witnessing parental violence (107.1 months), intimate partner or sexual violence (110.9 months), physical violence (101.1 months), war-related trauma (82 months) and other/private trauma (71.5 months). In a nationally representative sample of 8841 Australian adults, the 12-month prevalence of DSM-IV PTSD was 6.4\%, the most common of 13 individual common mental disorders (CMD) and accounted for $19 \%$ of the total CMD burden. ${ }^{2}$

Indigenous peoples of the world are generally considered to have increased risk of exposure to trauma ${ }^{3}$ and mental disorders, although many studies have lacked appropriate controls. In a systematic review and metaanalysis of the prevalence of depression and anxiety in Indigenous peoples of the Americas, Kisely and colleagues $^{4}$ found no overall increase of mental disorders compared with similar non-Indigenous controls. The standout result, however, came from four US and one Canadian study that showed increased risk of 12-month PTSD (OR 1.46, 95\% CI 1.28 to 1.69 ) in the Indigenous populations.

In an umbrella review of 33 systematic reviews or metaanalyses (238 studies), Tortella-Feliu and colleagues ${ }^{5}$ identified a number of risk factors for PTSD. In addition to the increased risk in Indigenous peoples, ${ }^{4}$ convincing evidence (class I) was found for a history of physical disease (equivalent OR, eOR 2.29) and family history of psychiatric disease (eOR 1.80). Highly suggestive evidence (class II) was found for cumulative trauma (eOR 5.24), trauma severity (eOR 3.32), being trapped (eOR 2.86), female gender (eOR 1.65), and suggestive evidence (class III) for torture (eOR 4.46) and a personal psychiatric history (eOR 2.45).

At least 800000 or $3.3 \%$ of Australians are of Aboriginal or Torres Strait Islander (Indigenous) heritage and the number will increase to 1 million by $2027 .{ }^{6}$ As a result of over two centuries of colonisation, Indigenous Australians are markedly disadvantaged in all respects, have much greater burden of disease ${ }^{7}$ and lifespan is reduced by at least 10 years. Compared with the general population, Indigenous Australians are 14 times more likely to be hospitalised and 7 times more likely to die due to assault; females are 33 times more likely to be hospitalised due to family violence. ${ }^{8}$ Indigenous Australian adolescents are also exposed to greater trauma. Their allcause mortality is more than twice that of non-Indigenous adolescents. The rate of fatal road-traffic accident is twice, suicide and fatal assault four times higher, hospitalisation due to accidental poisoning or exposure to fire/heat three times higher, and hospitalisation due to assault six times higher among Indigenous adolescents. ${ }^{9}$ Indigenous mortality is influenced by remoteness. Compared with non-Indigenous Australians, the age-specific all-cause mortality of Indigenous Australians living in Queensland increases by remoteness across all age groups. The Indigenous standardised mortality ratio is 188 (95\% CI 150 to 188 ) in major cities, unchanged at 142 (95\% CI 125 to
$161)$ in inner regional but, with increasing remoteness, progressively increases to 414 (95\% CI 223 to 280 ) in very remote areas. ${ }^{10}$

Based on limited data, mostly self-reported, Indigenous Australians are thought to have increased rates of mental disorders. Regrettably, the Indigenous population was not assessed in Federal Government-funded, nationally representative, adult nor child surveys of mental health that employed face-to-face diagnostic interviews. ${ }^{2}{ }^{11} \mathrm{~A}$ systematic review found that limited evidence exists on the prevalence of mental disorders in community-living Indigenous Australians. ${ }^{12}$ In the largest interview-based assessment of CMD among Indigenous Australians to date, we conducted Clinical Interview for DSM-IV-TR Axis I Disorders- Non-Patient Edition (SCID-I/NP, $1 / 2010$ revision) assessments ${ }^{13}$ in 544 Indigenous adults 18 years and older, living in metropolitan, regional and rural areas. ${ }^{14}$ We found that standardised rates of current mood, anxiety and substance use disorders were 6.7 -fold, 3.8-fold and 6.9-fold higher, respectively, than in the Australian general population. ${ }^{2}$ The crude prevalence of current, 12-month and lifetime PTSD of 13.8\%, 15.3\% and $20.8 \%$, respectively, were the highest of any individual CMD.

In a study of 221 Indigenous adults living in three very remote communities in Central West Western Australia, ${ }^{15}$ using a diagnostic interview (WHO CIDI) and other diagnostic tools to assess traumatic events, the prevalence of PTSD and alcohol abuse was determined. This study found that almost all participants $(97.3 \%)$ had been exposed to trauma, and lifetime prevalence of PTSD according to DSM-IV criteria was extraordinarily high at $55.2 \%$. Likewise, alcohol abuse or dependence is at $73.8 \%$. Of those with PTSD, $91 \%$ had comorbid alcohol use-related disorders. It was suggested that alcohol was being used as self-medication but excess alcohol would increase the risk of trauma exposure. The three communities were specifically selected based on 'observed level of trauma events' so the results may not be representative of all Indigenous peoples living remotely. In addition, only $11.9 \%$ of Australia's Indigenous population live in very remote areas. ${ }^{16}$

The only other large study to use a diagnostic interview (WHO CIDI) to assess trauma and PTSD in an Indigenous Australian population was conducted in 396 Indigenous Australians (331 males) in custody. ${ }^{17}$ The 12 -month crude prevalence of PTSD was $12.1 \%$ in males and $32.5 \%$ in females. Trauma experiences were common among the whole cohort (mean events 2.9 per capita) and about two times more common in those with PTSD. In males, the strongest associations with PTSD were sexual assault/ molestation (mean age 10-11 years), torture/terrorism, life-threatening accident and witness to bad injury or death. In females, it was sexual assault (mean age 15 years), sexual molestation (mean age 11 years) and physical attack, threatened with a weapon/kidnapped. An incarcerated sample, with only $16 \%$ female, may not be representative of the broader Indigenous community. 
Trauma exposure and PTSD have been studied in incarcerated and very remote living Indigenous Australian populations ${ }^{15} 17$ but little quantitative data on this important topic have been published for a community sample living in non-remote areas.

Our previous study ${ }^{14}$ investigated the prevalence of CMD as assessed by SCID-I, ${ }^{13}$ a semistructured interview that assesses the presence of psychiatric morbidity using diagnostic criteria from the Diagnostic and Statistical Manual of Mental Disorders, Fourth Edition (DSM-IV-TR). Our study showed that SCID-I was culturally valid in this particular Indigenous population. ${ }^{18}$ In addition to allowing the diagnosis of CMD, the SCID-I interviews quantified trauma exposures of all participants. The current study examines the prevalence of traumatic life events and associations between types of trauma, other exposures and PTSD.

\section{METHODS}

\section{Study design}

A cross-sectional prevalence study of Indigenous Australians aged 18 years and older was conducted between July 2014 and November 2016; participant recruitment and involvement procedures have previously been detailed. ${ }^{14}$ The geographical location of recruitment was classified according to the Australian Standard Geographical Classification-Remoteness Areas (ASGC-RA), ${ }^{19}$ with RA1 being major cities, RA2 inner regional, RA3 outer regional, RA4 remote and RA5 very remote. 'Metropolitan' is used to describe RA1 and 'Rural' to describe RA2 to RA5. Participants (18 years and older) were recruited across an area of approximately $150000 \mathrm{~km}^{2}$ located in South-Eastern Queensland and North-Eastern New South Wales, from sites that were located in a capital city (RA1, $15 \%)$, a large regional city and three regional towns (RA2-3, 56\%), the remainder (29\%) from a remote town (RA4), two Aboriginal Reserves (RA3) and other communities in outer regional and remote areas (RA3-4). In these sites, the proportion of the population that were Indigenous ranged from $<1 \%$ to $>90 \%$. In the cities and towns where only $1 \%-4 \%$ are Indigenous, the recruitment sites were Aboriginal Medical Services (AMS), which is the only feasible way to recruit a minority group. Although health is the main activity of these centres, much of this is preventative health, and many cultural, social and educational activities occur. The centres are quite unlike mainstream medical clinics and those attending are often not seeking treatment.

Participants were recruited by Indigenous support workers (ISWs) who were community members. Interviews were conducted in private in AMS or other local facilities considered being 'safe places' (for Indigenous people). Participants were asked if they would like to have an ISW present in the interview room and an ISW was always available, if not present. Interviews were conducted by clinical psychologists or Masters of Psychology candidates-supervised by a senior academic clinical psychologist (GB) who also provided quality control of all SCID interviews. All interviewers were trained in Indigenous Cultural Awareness and in administration of SCID. A senior Aboriginal academic (MT) supervised cultural matters.

In the SCID-I PTSD module, a component of the interview procedure, trauma is assessed by an item that first provides a definition of trauma and examples of traumatic events (such as a major natural disaster, physical or sexual violence, and more), and then asks whether the participant has experienced any such events. The interview assessment involves types of events experienced, along with age and/or date of occurrence. If the interviewee does not report any trauma, probes enquire as to whether he or she has ever been in a car accident or a victim of a crime. Events were defined as trauma if they met the following DSM-IV-TR and SCID-I PTSD criterion: 'The person experienced, witnessed, or was confronted with an event or events that involved actual or threatened death or serious injury, or a threat to the physical integrity of self or others. ${ }^{20}$ The data and categories were reviewed by a senior clinical psychologist (GB and EB) and senior consultant psychiatrist (SK) during development.

\section{Data analysis}

Descriptive analysis was undertaken to identify the demographic characteristics of the participants. Crude prevalence rates of traumatic life events and their association with PTSD were stratified by age and gender. The 2001 Australian General Population standard ${ }^{19}$ was used to determine standardised prevalence rates. Standardised prevalence rates were compared with studies reporting the 2007 Australian National Survey of Mental Health and Well-being (NSMHWB). ${ }^{21}$ Multiple logistic regression analysis was performed to determine the risk of PTSD associated with various trauma categories (online supplemental table 1) and other exposures.

\section{Patient involvement}

Participants of the study were not involved in the design, implementation or evaluation of this particular study. Participant involvement procedures for the overall project have been detailed in a prior publication. ${ }^{14}$

\section{RESULTS}

\section{Participant characteristics}

Sixty-two per cent of the cohort were female. The age distribution was similar to that of the general Indigenous population of Australia aged 18+ years, ${ }^{14}{ }^{19}$ although those $65+$ years were over-represented $(8.8 \%$ vs $4.2 \%$ of all Indigenous Australians). Those living in major cities or remote/very remote areas were under-represented ( $15.2 \%$ vs $37.4 \%$ and $4.6 \%$ vs $18.6 \%$, respectively).

\section{Prevalence and types of trauma}

Of the 544 participants, $64.9 \%$ reported any lifetime traumatic event that met the DSM-IV criteria (table 1). There 


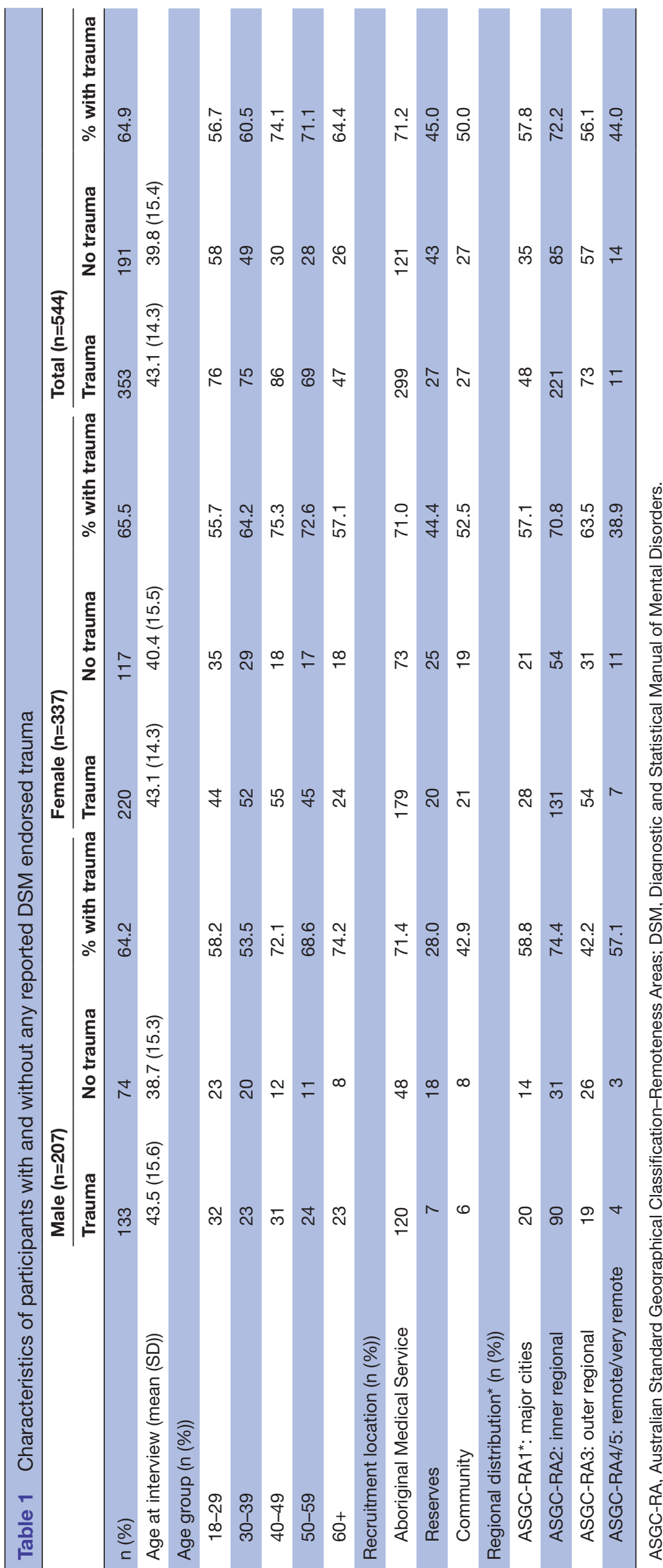

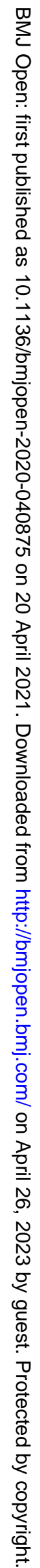


Table 2 Type and frequency of trauma reported

\begin{tabular}{|c|c|c|c|c|c|c|c|}
\hline \multirow{2}{*}{$\begin{array}{l}\text { Traumatic event type* } \\
\text { (n (\%)) }\end{array}$} & \multirow{2}{*}{$\begin{array}{l}\begin{array}{l}\text { Male } \\
(n=133)\end{array} \\
N(\%)\end{array}$} & \multirow{2}{*}{$\begin{array}{l}\text { Female } \\
(\mathrm{n}=220)\end{array}$} & \multirow{2}{*}{$\begin{array}{l}\begin{array}{l}\text { Total } \\
(\mathrm{n}=353)\end{array} \\
\mathrm{N}(\%)\end{array}$} & \multirow[b]{2}{*}{$P$ value } & \multirow{2}{*}{$\begin{array}{l}\begin{array}{l}\text { Standardised } \\
\text { prevalence }\end{array} \\
\% \\
\end{array}$} & \multirow{2}{*}{$\begin{array}{l}\begin{array}{l}\text { Australian } \\
\text { population } \dagger \\
(\mathrm{n}=8841)\end{array} \\
\%\end{array}$} & \multirow[t]{2}{*}{ Rate ratio } \\
\hline & & & & & & & \\
\hline Sexual violence & $23(17.3)$ & $89(40.5)$ & $112(31.7)$ & $<0.001$ & 18.7 & 8.5 & 2.2 \\
\hline Physical violence & $73(54.9)$ & $123(55.9)$ & $196(55.5)$ & 0.851 & 34.4 & 11.5 & 3 \\
\hline Non-interpersonal & $62(46.6)$ & $104(47.3)$ & $165(47)$ & 0.45 & 29.5 & 10.6 & 2.8 \\
\hline Witnessing death/suicideł & $11(8.3)$ & $19(8.6)$ & $30(8.5)$ & 0.519 & 5.5 & $\mathrm{n} / \mathrm{a}$ & $\mathrm{n} / \mathrm{a}$ \\
\hline Private trauma & $3(2.3)$ & $6(2.7)$ & $9(2.5)$ & 0.532 & 1.4 & $\mathrm{n} / \mathrm{a}$ & $\mathrm{n} / \mathrm{a}$ \\
\hline Any trauma & $133(37.7)$ & $220(62.3)$ & $353(100)$ & & 62.6 & 73.8 & 0.85 \\
\hline
\end{tabular}

*Multiple traumatic events may have occurred for participants.

†Afzali et al. ${ }^{23}$

‡Does not include unexpected death of a loved one.

was a higher prevalence of trauma in those recruited from an AMS compared with those from reserves or community. Participants from inner regional areas (ASGC-RA2) ${ }^{22}$ reported more trauma than those from other geographical locations. Female and male participants aged 40-59 and male participants 60 years and older reported the most trauma.

The most commonly reported trauma was physical violence $(55.5 \%)$ (table 2). Females experienced significantly higher crude rates of any trauma largely due to their higher rates of sexual violence (over twofold), but no other gender differences were apparent. Most trauma occurred during adolescence, with $27.2 \%$ of all participants reporting once only trauma between age 11 and 20 years. More than once trauma was most commonly reported between age 11 and 30 years. The age of reported trauma progressively declined with age above $20-30$ years (table 3 ).

When standardised against the Australian population, the rate of any reported trauma was $62.9 \%$ (CI 56.3 to 69.4 ) in males and $61.1 \%$ (CI 55.9 to 66.3 ) in females, $62.6 \%$ (CI 58.6 to 66.7) overall. By comparison, in a nationally representative sample of 8841 Australians that also used DSM-IV criteria, $73.8 \%$ reported any lifetime trauma. ${ }^{21}$ Using the same database, Afzali ${ }^{23}$ et al reported traumas in four conceptually related categories-sexual violence (rape, sexual assault), physical violence (physical assault, childhood physical abuse, threatened with a weapon, kidnapped), non-interpersonal (life-threatening accident, natural disaster, exposure to toxic chemical) and unexpected death of a loved one. Compared with rates reported in this study, our Indigenous cohort experienced substantially higher rates of these trauma categories: 2.2-fold, 2.8-fold, 2.5-fold and 1.4-fold higher, respectively. The standardised rates of sexual and physical violence were not different in those recruited from the major city compared with elsewhere ('rural'), but the rates of unexpected death of a loved one and non-interpersonal trauma were substantially lower in the major city (rate ratios 0.25 and 0.61 , respectively) (table 2).

\section{Childhood trauma}

The standardised prevalence of any reported trauma before the age of 9 years was $19.5 \%$ and before the age of

Table 3 Age of reported trauma (n (\%))

\begin{tabular}{|c|c|c|c|c|c|c|}
\hline \multirow[b]{3}{*}{ Decade of life } & \multicolumn{2}{|c|}{ Male $(n=207)$} & \multicolumn{2}{|c|}{ Female $(n=337)$} & \multicolumn{2}{|c|}{ Total $(n=544)$} \\
\hline & Once only & More than once & Once only & More than once & Once only & More than once \\
\hline & N (\%) & N (\%) & N (\%) & $\mathbf{N}(\%)$ & N (\%) & N (\%) \\
\hline $11-20$ years & $51(24.6)$ & $12(5.8)$ & 97 (28.8) & $18(5.3)$ & $148(27.2)$ & $30(5.5)$ \\
\hline 21-30 years & $41(19.8)$ & $13(6.3)$ & 74 (22) & $20(5.9)$ & $115(21.1)$ & $33(6.1)$ \\
\hline $41-50$ years & $12(5.8)$ & $8(3.9)$ & 31 (9.2) & $8(2.4)$ & $43(7.9)$ & $16(2.9)$ \\
\hline $51-60$ years & $2(1)$ & $5(2.4)$ & $10(3)$ & $12(3.6)$ & $12(2.2)$ & $17(3.1)$ \\
\hline $61+$ years & $4(1.9)$ & $1(0.5)$ & $2(0.6)$ & $4(1.2)$ & $6(1.1)$ & $5(0.9)$ \\
\hline
\end{tabular}

Trauma may have occurred during multiple decades of life; does not include participants who did not report/remember decade of life when trauma occurred. 


\section{$N=353$}

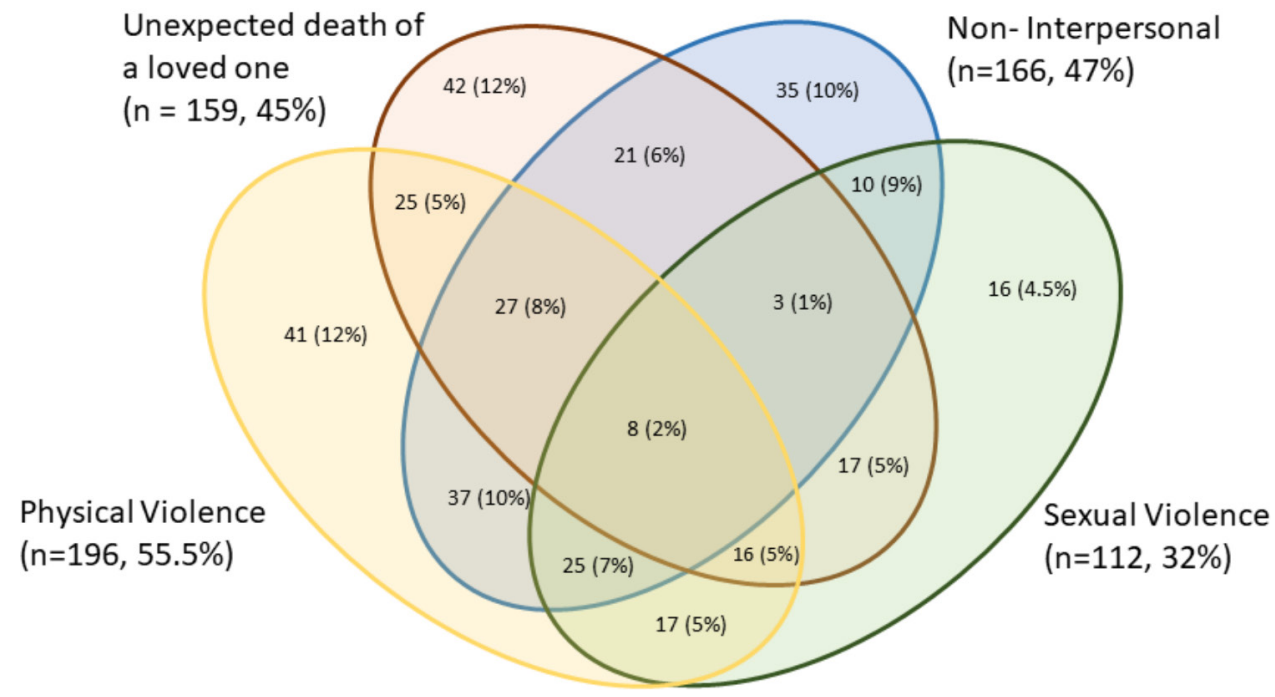

Figure 1 Comorbid trauma types. The trauma categories witnessing death/suicide $(n=30,8.5 \%)$ and private trauma $(n=9$, $2.5 \%$ ) are not included in this figure.

17 years was $33.8 \%$, which are not substantially different from the rates of $20 \%$ and $41 \%$, respectively, reported in a national representative sample of Australian adults. ${ }^{24}$ The standardised prevalence of reported sexual abuse before age 15 years was $14.6 \%$, of physical abuse $17.3 \%$ and of any sexual and/or physical abuse $23.1 \%$. These rates are approximately twice those reported in the Australian general population by the Australian Bureau of Statistics $\left(7.7 \%, 8.5 \%, 13.4 \%\right.$, respectively).$^{25}$

\section{Multiple trauma categories}

Almost two-thirds $(62.3 \%)$ of those reporting traumas experienced more than one category of trauma. Two categories $37.7 \%$, three categories $21.5 \%$ and four categories $2.8 \%$. No participants reported more than four categories of trauma. The average number of trauma types was 1.9 per capita.

The exposure to multiple categories of trauma in most participants is apparent from figure 1 .

\section{Post-Traumatic stress disorder}

DSM-IV criteria for the crude prevalence of a 30-day, 12-month and lifetime diagnosis of PTSD was met in $21.2 \%, 23.5 \%$ and $32.0 \%$ of participants, respectively. Standardised prevalence rates were $12.0 \%, 13.3 \%$ and $19.9 \%$, respectively.

Compared with the general Australian population, ${ }^{26}$ the risks of the 12-month and lifetime PTSD were 3.0-fold and 2.7-fold higher, respectively.

\section{Associations between trauma and PTSD}

We used multiple regression models to examine associations between trauma, other exposures and 12-month PTSD. Since most participants reported experiencing traumas in multiple trauma categories, the regression only included groups who had (1) experienced sexual violence without physical violence $(n=46) ;(2)$ experienced physical violence without sexual violence $(n=130)$; or (3) experienced sexual violence and physical violence $(n=66)$, the reference group being those who had never experience sexual or physical violence $(n=111)$.

In univariate regression analysis, female gender, rural residence, childhood trauma, sexual violence only, physical violence only, and both sexual and physical violence only predicted PTSD (table 4).

In multiple regression analysis, all these exposures were independent predictors of PTSD with ORs >2.0 (table 4). The combination of both sexual and physical violence was associated with the highest risk of developing PTSD (OR 5.02).

\section{DISCUSSION}

In this Indigenous Australian cohort, we found that the standardised prevalence of any lifetime trauma was $62.6 \%$, which may be somewhat lower than the $74.9 \%$ reported from a national Australian sample ${ }^{27}$ and the $70.4 \%$ reported from a worldwide sample. ${ }^{1}$ The rates of sexual violence, physical violence and non-interpersonal (experiencing or witnessing serious accidents or disasters), however, were 2.2 to 2.8 times higher than in the Australian sample. In our previous report on this cohort, ${ }^{14}$ we found that the markedly increased rates of current CMD in the Indigenous group compared with the Australian population were substantially less for 12-month and lifetime CMD, and argued that previous events have lower salience in Indigenous Australians. Thus, it is possible that they are more likely to recall only severe or particular types of traumas. The prevalence of 'private' traumas was $1.4 \%$ in the Indigenous sample but three times higher $(4.7 \%)$ in the Australian sample, which may reflect the Indigenous concept of 'shame' 28 and may have resulted in under-reporting of some traumas. 
Table 4 Regression analyses for the association of risk factors with a 12-month diagnosis of PTSD ( $n=353)$

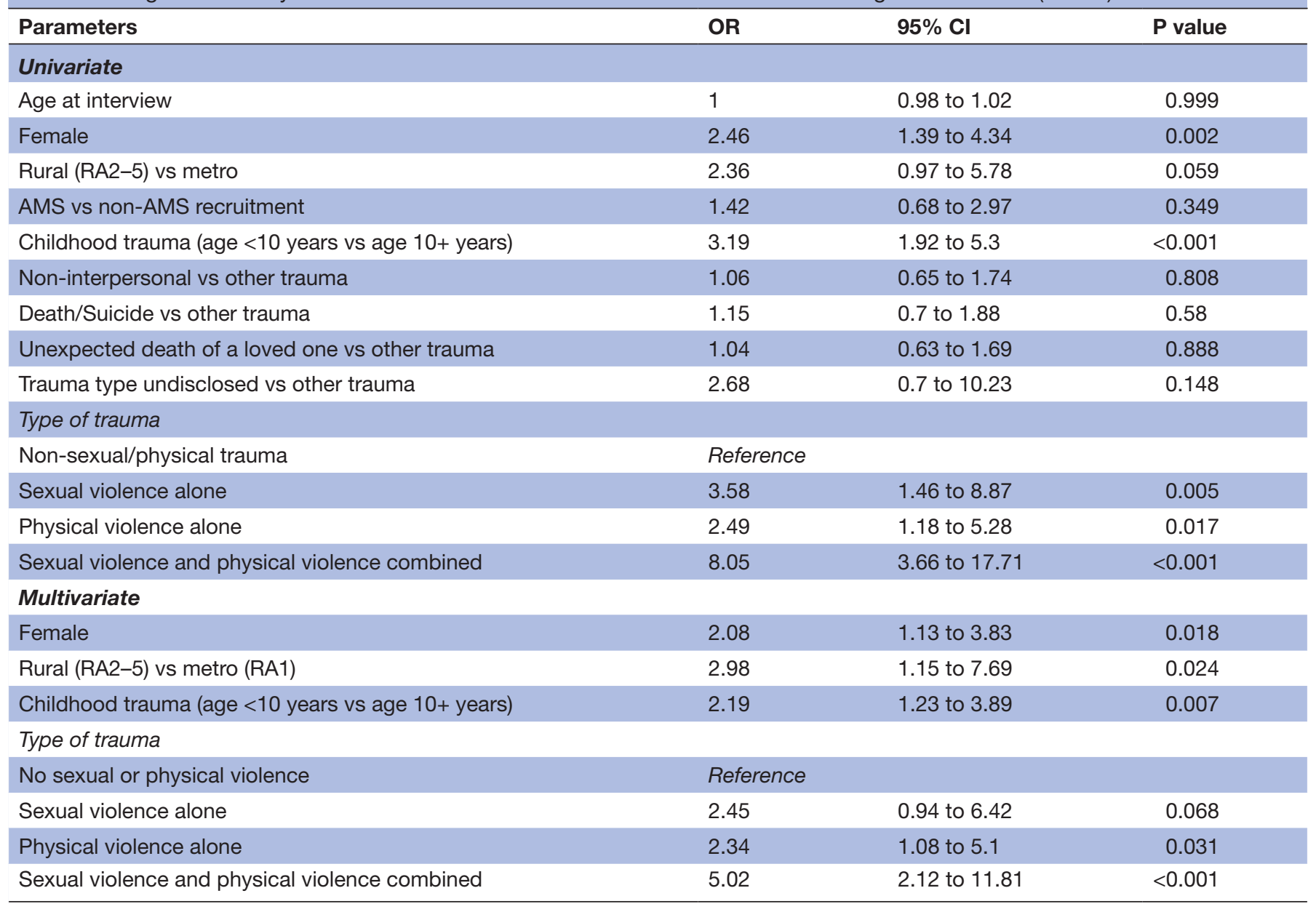

AMS, Aboriginal Medical Services; PTSD, post-traumatic stress disorder.

The most commonly reported category of trauma was physical violence, with more than half of both males and females reporting experiencing this category of trauma. Not surprisingly, females experienced higher rates of sexual violence than males. In a nationally representative sample of 4451 Australian women, ${ }^{29}$ the lifetime prevalence of rape was $8.1 \%$ and sexual assault $14.7 \%$ (correlation $0.59, \mathrm{p}<0.05$ ) so the rate of sexual violence (rape or sexual assault) of $40 \%$ in our Indigenous cohort is likely more than twice that of other Australian women. Notably, this study found that gender-based violence was an independent predictor of lifetime DSM-IV PTSD (OR 4.43, 95\% CI 3.18 to 6.17 ). The median age of first occurrence of rape was 13 years and of sexual assault 12 years, so sexual violence commonly occurred in childhood. ${ }^{29}$

Although the prevalence of any childhood trauma (before age 9 years or before age 17) in this Indigenous cohort is similar to those reported for the Australian population, ${ }^{24}$ the prevalence of sexual or physical violence before age 15 years was twice that of the general population. ${ }^{25}$

The standardised prevalence of the 12-month PTSD in this cohort was $13.3 \%$, which is 3.0 -fold higher than that in the Australian population. ${ }^{26}$ Indigenous females have had twice the risk of PTSD than males. These findings are consistent with prior research finding that Australian females generally have higher rates of PTSD. ${ }^{30} 31$ This has been proposed to be a function of trauma type, as women are more likely to experience sexual and intimate partner violence. $^{31}$

The study by Heffernan $e^{~} \mathrm{al}^{17}$ of 396 Indigenous Australians in custody reported PTSD rates of $12.1 \%$ in males and $32.3 \%$ in females. When standardised against the Australian population by gender and age, although using the limited age data available, the rates would be approximately $11 \%$ and $28 \%$, respectively. Thus, standardised rates of PTSD in our community sample are not different from those in an incarcerated sample of similar size. This unexpected finding perhaps reflects the generalisation of trauma and PTSD across Australia's Indigenous communities. It is relevant that the standardised imprisonment rate of Indigenous Australians is 13 times greater than the rate of non-Indigenous Australians ${ }^{32}$ so incarcerated and non-incarcerated Indigenous Australians may be less different than these two groups of non-Indigenous Australians, but subjected to more discrimination and oppression. 
The National Aboriginal and Torres Strait Islander Social Survey 2014-2015 (NATSISS) ${ }^{33}$ found that the rates of mental disorder varied by region, with those in remote areas self-reporting lower rates of disorder. Similarly, other research has found Indigenous Australians living in remote areas report less psychological distress than those who live in other regions. ${ }^{34}$ The regional distributions of those with reported trauma in this cohort are therefore consistent with previous research. As lower rates of trauma and PTSD were obtained for participants living in remote Indigenous communities, living on traditional lands (on country) appears to be a protective factor. Participating in cultural activities related to country has been linked to significantly better health for Indigenous Australians. When this variable was controlled for, living on country, however, was associated with worse health outcomes. ${ }^{35}$ Consistent with this, the NATSISS also found that Indigenous Australians without a mental health condition had higher rates of participation in cultural activities and language speaking. This participation, however, was also tied to geography, so that people living remotely had higher rates of cultural participation (and lower rates of disorder) than those living in other areas. We found lower rates of current mood and anxiety disorders in participants living on Aboriginal reserves, where Indigenous people are the majority and they are generally on country. ${ }^{14}$ Therefore, it may be that connection to culture and country, rather than simply living on country, is actually what forms a unique protective factor for Indigenous Australians.

We found that living in a major city compared with rurally is protective of developing PTSD (OR 3). This contrasts with our previous finding of no effect of geographical location on the rates of current CMD, except in the very small proportion $(4.5 \%)$ living in remote/very remote areas who had a quarter the rate of any current CMD. ${ }^{14}$ Notably, Australia's mental health workforce is concentrated in major cities-compared with major cities, full time equivalent (FTE) per 100000 population for psychiatrists is $60 \%$ lower in regional and remote areas and $80 \%$ lower in very remote area. For psychologists, there are progressive reductions in FTE from $42 \%$ lower in inner regional to $77 \%$ lower in very remote areas. ${ }^{36}$ Mental healthcare of Indigenous population is almost exclusively by general practitioners and psychologists. Outside of major cities, psychiatry services are provided by regional state government public hospitals for major psychotic disorders, but not CMD.

In the whole cohort, sexual and physical violence are strong independent, and additive, predictors of PTSD, and are not different in the metropolitan (RA1) and rural (RA2-5) areas. Exposure to the unexpected death of a loved one, however, was markedly increased in rural residents, which may contribute to their threefold higher rate of PTSD. Compared with major cities, death due to all types of injury (including suicide, motor vehicle accident, violence, shooting) is 1.2-fold to 2.4-fold higher in rural areas (increasing with increasing remoteness) and 3-fold to 4-fold higher in Indigenous Australians compared with non-Indigenous Australians. Seventy per cent of Indigenous Australians live in rural areas compared with $30 \%$ of non-Indigenous Australians. Thus, it is not unexpected that witnessing the death of a loved one is much more likely for Indigenous Australians living in rural areas than any other group.

The European colonisation of Australia and racism have resulted in forced removal of the Indigenous population from traditional lands and children from parents ('stolen generation'), together with genocide, marginalisation, injustice, deprivation, loss of identity and much more. ${ }^{37}$ This has resulted in 'collective trauma', ${ }^{38}$ or 'historical/intergeneration trauma'. ${ }^{39}$ The appropriateness of diagnostic criteria and treatment of PTSD in the context of collective trauma has been questioned. ${ }^{40} 41$ Perhaps a more appropriate diagnosis for our Indigenous population is complex post-traumatic stress disorder (CPTSD) recently recognised in ICD-11 but not in DSM- $5 .{ }^{42}$ In a study of Syrian refugees, CPTSD was diagnosed in $36.1 \%$ and PTSD in $25.2 \%$, the total being considerably higher than the $30 \%$ diagnosed with DSM-5 PTSD in a metaanalysis of refugee studies. ${ }^{43}{ }^{44}$ Future research in Indigenous populations should quantify the types, numbers and age of exposure of trauma in detail and the presence of intergenerational trauma, which will require family studies. In addition, the presence of both CPTSD and DSM-5 PTSD should be assessed.

\section{LIMITATIONS}

Our study was conducted according to DSM-IV-TR criteria for trauma and PTSD, which have been revised in the next version, DSM-5. ${ }^{45}$ This revision significantly changed the PTSD construct, ${ }^{46}$ including changes to symptom clusters and a more explicit definition of trauma (now with specific examples). Lower rates of PTSD have been found when DSM-5 is used. ${ }^{47}$ It is likely that applying the DSM-5 trauma and PTSD constructs to our data would have produced different outcomes. Further, DSM is a Western classification system and it has been argued that the diagnostic criteria may not be transferable to an Indigenous context. ${ }^{49}$ Comparison of our results with findings from the NSMHWB should be interpreted with caution because of methodological differences (ie, SCID vs CIDI and reporting of standardised prevalence rates vs a complex survey design used by NSMHWB 2007). In particular, the CIDI specifically enquires about exposure to a range of specific traumas, whereas the SCID first describes the types of trauma people may be exposed to and then asks the subjects whether any of these things have ever happened to them. It is therefore possible that the SCID used in this study might have underestimated the rates of trauma and PTSD, and those differences between Indigenous Australians and the general population are even greater than shown by this study.

As trauma data were collected retrospectively, recall bias may be present. Recall of trauma may also have been 
influenced by the current mental state of participants and by the Indigenous concept of 'shame'. ${ }^{28}$ There may be recruitment bias, given that opportunistic recruitment was used.

By Indigenous Australian mental health research standards, this is a large study. Nevertheless, the study is not powered to determine associations between all types of traumas, other exposures identified and PTSD. In addition, other exposures possibly associated, for example, forced removal from parents or removal from traditional lands, have not been assessed. The possibility of other important yet unknown exposures cannot be excluded.

A potential limitation in this study is that we did not control for any measures of socioeconomic status (SES). It is well established that Indigenous Australians are markedly disadvantaged in all measures of the social gradient ${ }^{50}$ and these factors are likely to contribute to their increased burden of harmful trauma and PTSD. An issue for Indigenous studies incorporating SES is that almost all of the population is in the lowest levels of SES. Exposures other than SES (a Western construct), such as racism, marginalisation, kinship network, connection to culture and traditional lands, and others, may be more important. ${ }^{51}$ Very few studies have examined the relationship between SES and health among Indigenous Australians and those that have found that the relationship is 'less universal and less consistent' than in non-Indigenous studies. ${ }^{51}$ Importantly, the aim of our study was to determine rates of trauma and the risk of PTSD in an Indigenous population and establishing a causal relationship is beyond its scope.

Although the sample is broadly representative of Indigenous peoples living in Southern Queensland/Northern New South Wales, it may not be representative of the Australian Indigenous population as a whole due to the diversity of cultures, languages and histories within this population. In particular, the sample may not be representative of the $18.6 \%$ of Indigenous Australians who live in remote or very remote areas of Australia, where specific challenges exist, and English is often the second or third language.

\section{CONCLUSIONS}

Although this Indigenous cohort reported a lower overall rate of any trauma exposure than the Australian population, and the same rate of any trauma in childhood, higher rates of specific categories of trauma were reported, particularly sexual and physical violence (including exposure before the age of 15 years), non-interpersonal and unexpected death of a loved one. The standardised 12-month prevalence of PTSD was three times that of the Australian population. Although not assessed in this study, the new ICD-11 diagnosis of CPTSD may be more appropriate for this Indigenous population and other populations exposed to collective or intergenerational traumas.

Independent predictors of the 12-month PTSD were female gender, rural residence, trauma exposure in childhood ( $<10$ years), physical violence and sexual violence.
Exposure to both physical and sexual violence doubled the risk of either alone. The adverse effect of rural residence may be related to the much higher incidence of trauma related to the unexpected death of a loved one.

Our study shows that the prevalence of potentially more harmful traumas and PTSD in this Indigenous cohort is twice that of the general Australian population. Urgent attention by Australian communities and governments to the underlying social determinants of sexual and physical violence and other traumas, particularly in childhood, is urgently required to break the intergenerational cycle leading to the existing tragic situation.

\section{Author affiliations}

${ }^{1}$ Rural Clinical School, Faculty of Medicine, The University of Queensland, Toowoomba, Queensland, Australia

${ }^{2}$ Princess Alexandra Hospital Southside Clinical Unit, Faculty of Medicine, The University of Queensland, Brisbane, Queensland, Australia

${ }^{3}$ School of Psychology and Counselling, University of Southern Queensland, Toowoomba, Queensland, Australia

Acknowledgements The authors acknowledge the study participants who contributed their time in completing the assessment interviews. The authors thank the Aboriginal Medical Services staff and the strong support of Aboriginal Community Elders and Leaders who facilitated the implementation and conduct of the research. The authors also thank the Masters of Psychology candidates for their contribution to conducting the assessment interviews.

Contributors BFN: Project manager, data collection, database maintenance, statistical analyses, manuscript drafts and final version of the manuscript writing. EB: Clinical psychologist responsible for conducting the participant assessments and data collection, and final approval of the manuscript. MT: Senior Aboriginal academic, principal chief investigator; concept, design engagement and final approval of the manuscript. SK: Senior clinical psychiatrist, provided assessment supervision and oversight, concept, design and approval of the final manuscript. NG: Clinical psychiatrist, provided assessment supervision and oversight, approval of the final manuscript. GB: Senior psychologist, provided assessment supervision and oversight, concept, design and approval of the final manuscript. SK-C: Senior academic, supervision of the epidemiology and biostatistics, editing and approval of the final manuscript. GN: Senior academic, supervision of the epidemiology and biostatistics, editing and approval of the final manuscript.

Funding This study was funded by the National Health and Medical Research Council, Australia, Project Grant 1061963.

Disclaimer The study funder had no role in the study design, planning, data collection, analysis, interpretation or manuscript preparation for this study.

Competing interests MT is an Aboriginal woman who is Chair of the Board of one of the participating AMS but played no role in the decision of the AMS to participate in the study.

\section{Patient consent for publication Not required.}

Ethics approval The University of Queensland Human Research Ethics Committee approved the study (Clearance Number: 2012001315) as did the Boards of Directors of the participating Aboriginal Medical Services. Permission from Indigenous Elders was obtained prior to recruiting from Reserves and Communities. The study was conducted in accordance with the National Health and Medical Research Council of Australia Guidelines (Values and Ethics: Guidelines for Ethical Conduct in Aboriginal and Torres Strait Islander Health Research, 2003).

Provenance and peer review Not commissioned; externally peer reviewed.

Data availability statement Data are available on reasonable request. The University of Queensland (UQ) Human Ethics Committee imposes restrictions on the data. Anonymised data are available to researchers who meet the conditions of the ethics approval and research governance policy that applies to this study via UQ eSpace. Requests for the data may be sent to the Director of Research, Rural Clinical School, UQ (rcsrc@ uq.edu.au).

Supplemental material This content has been supplied by the author(s). It has not been vetted by BMJ Publishing Group Limited (BMJ) and may not have been 
peer-reviewed. Any opinions or recommendations discussed are solely those of the author(s) and are not endorsed by BMJ. BMJ disclaims all liability and responsibility arising from any reliance placed on the content. Where the content includes any translated material, BMJ does not warrant the accuracy and reliability of the translations (including but not limited to local regulations, clinical guidelines, terminology, drug names and drug dosages), and is not responsible for any error and/or omissions arising from translation and adaptation or otherwise.

Open access This is an open access article distributed in accordance with the Creative Commons Attribution Non Commercial (CC BY-NC 4.0) license, which permits others to distribute, remix, adapt, build upon this work non-commercially, and license their derivative works on different terms, provided the original work is properly cited, appropriate credit is given, any changes made indicated, and the use is non-commercial. See: http://creativecommons.org/licenses/by-nc/4.0/.

\section{ORCID IDs}

Bushra F Nasir http://orcid.org/0000-0002-8372-4877

Steve Kisely http://orcid.org/0000-0003-4021-2924

Neeraj Gill http://orcid.org/0000-0003-2106-9843

\section{REFERENCES}

1 Kessler RC, Aguilar-Gaxiola S, Alonso J, et al. Trauma and PTSD in the who world mental health surveys. Eur J Psychotraumatol 2017;8:1353383.

2 Slade T, Johnston A, Oakley Browne MA, et al. 2007 national survey of mental health and wellbeing: methods and key findings. Aust N Z J Psychiatry 2009;43:594-605.

3 Nettleton C, Napolitano DA, Stephens C. An overview of current knowledge of the social determinants of Indigenous health: working paper. Geneva: World Health Organisation, 2007.

4 Kisely S, Alichniewicz KK, Black EB, et al. The prevalence of depression and anxiety disorders in Indigenous people of the Americas: a systematic review and meta-analysis. J Psychiatr Res 2017;84:137-52.

5 Tortella-Feliu M, Fullana MA, Pérez-Vigil A, et al. Risk factors for posttraumatic stress disorder: an umbrella review of systematic reviews and meta-analyses. Neurosci Biobehav Rev 2019;107:154-65.

6 Australian Bureau of Statistics. Estimates and projections, Aboriginal and Torres Strait Islander Australians: estimates and projections of the Aboriginal and Torres Strait Islander population for 2006 to 2031. includes projections by sex and age groups. Canberra: ABS, 2019.

7 Australian Institute of Health and Welfare. The health and welfare of Australia's Aboriginal and Torres Strait Islander peoples 2015. Canberra: AlHW, 2015.

8 Australian Institute of Health and Welfare. Indigenous community safety. Canberra: AlHW, 2019.

9 Azzopardi PS, Sawyer SM, Carlin JB, et al. Health and wellbeing of Indigenous adolescents in Australia: a systematic synthesis of population data. Lancet 2018;391:766-82.

10 Andreasyan K, Hoy WE, Kondalsamy-Chennakesavan S. Indigenous mortality in remote Queensland, Australia. Aust N Z J Public Health 2007;31:422-7.

11 Lawrence D, Hafekost J, Johnson SE, et al. Key findings from the second Australian child and adolescent survey of mental health and wellbeing. Aust N Z J Psychiatry 2016;50:876-86.

12 Black EB, Ranmuthugala G, Kondalsamy-Chennakesavan S, et al. A systematic review: identifying the prevalence rates of psychiatric disorder in Australia's Indigenous populations. Aust N Z J Psychiatry 2015;49:412-29.

13 First M, Spitzer R, Gibbon M. Structured clinical interview for DSM-IV-TR axis I Disorders- non-patient edition (SCID-I/NP, 1/2010 revision). New York: Biometrics Research Department, New York State Psychiatric Institute, 2010.

14 Nasir BF, Toombs MR, Kondalsamy-Chennakesavan S, et al. Common mental disorders among Indigenous people living in regional, remote and metropolitan Australia: a cross-sectional study. BMJ Open 2018;8:e020196.

15 Nadew GT. Exposure to traumatic events, prevalence of posttraumatic stress disorder and alcohol abuse in aboriginal communities. Rural Remote Health 2012;12:1667.

16 Australian Bureau of Statistics. Estimates of aboriginal and torres strait islander Australians. 2016. Canberra: ABS, 2016.

17 Heffernan E, Andersen K, Davidson F, et al. Ptsd among aboriginal and torres strait Islander people in custody in Australia: prevalence and correlates. J Trauma Stress 2015;28:523-30.
18 Toombs M, Nasir B, Kisely S, et al. Cultural validation of the structured clinical interview for diagnostic and statistical manual of mental disorders in Indigenous Australians. Australas Psychiatry 2019;27:362-5.

19 Australian Institute of Health and Welfare. Principles on the use of direct age-standardization in administrative data collections: for measuring the gap between Indigenous and non-Indigenous Australians. Canberra: AlHW, 2011.

20 American Psychiatric Association. Diagnostic and statistical manual of mental disorders. 4 edn. Washington, DC: American Psychiatric Association, 2000.

21 Mills KL, Teesson M, Ross J, et al. Trauma, PTSD, and substance use disorders: findings from the Australian national survey of mental health and well-being. Am J Psychiatry 2006;163:652-8.

22 Australian Bureau of Statistics. Australian statistical geography standard (ASGS): volume 5 - remoteness structure. Canberra: ABS, 2011.

23 Afzali MH, Sunderland M, Batterham PJ, et al. Trauma characteristics, post-traumatic symptoms, psychiatric disorders and suicidal behaviours: results from the 2007 Australian national survey of mental health and wellbeing. Aust N Z J Psychiatry 2017;51:1142-51.

24 Barrett EL, Teesson M, Chapman C, et al. Substance use and mental health consequences of childhood trauma: an epidemiological investigation. Drug Alcohol Depend 2015;146:e217-8.

25 Australian Bureau of Statistics. Personal safety, Australia, 2016. Canberra: ABS, 2017.

26 McEvoy PM, Grove R, Slade T. Epidemiology of anxiety disorders in the Australian general population: findings of the 2007 Australian national survey of mental health and wellbeing. Aust N Z J Psychiatry 2011;45:957-67.

27 Mills KL, McFarlane AC, Slade T, et al. Assessing the prevalence of trauma exposure in epidemiological surveys. Aust N Z J Psychiatry 2011;45:407-15.

28 Louth S. Indigenous Australians: Shame and Respect. In: Vanderheiden E, ed. The value of shame. Springer, 2017: 187-200.

29 Rees S, Silove D, Chey T, et al. Lifetime prevalence of gender-based violence in women and the relationship with mental disorders and psychosocial function. JAMA 2011;306:513-21.

30 Ditlevsen DN, Elklit A. Gender, trauma type, and PTSD prevalence: a Re-analysis of 18 Nordic convenience samples. Ann Gen Psychiatry 2012;11:26-6.

31 Nemeroff CB, Bremner JD, Foa EB, et al. Posttraumatic stress disorder: a state-of-the-science review. J Psychiatr Res 2006;40:1-21.

32 Australian Bureau of Statistics. Prisoners in Australia 2018. Canberra: ABS, 2018

33 Australian Bureau of Statistics. 4714.0 national Aboriginal and Torres Strait Islander social survey, 2014-15. Canberra: ABS, 2016.

34 Cunningham J, Paradies YC. Socio-demographic factors and psychological distress in Indigenous and non-Indigenous Australian adults aged 18-64 years: analysis of national survey data. BMC Public Health 2012;12:1-15.

35 Burgess CP, Johnston FH, Berry HL, et al. Healthy country, healthy people: the relationship between Indigenous health status and "caring for country". Med J Aust 2009;190:567-72.

36 Australian Institute of Health and Welfare. Mental health services in Australia. Canberra: AlHW, 2020.

37 Parker R. Australia's Aboriginal population and mental health. J Nerv Ment Dis 2010;198:3-7.

38 Krieg A. The experience of collective trauma in Australian Indigenous communities. Australas Psychiatry 2009;17:S28-32.

39 Heart MYHB, Chase J, Elkins J, et al. Historical trauma among Indigenous peoples of the Americas: concepts, research, and clinical considerations. J Psychoactive Drugs 2011;43:282-90.

40 Somasundaram D. Collective trauma in northern Sri Lanka: a qualitative psychosocial-ecological study. Int J Ment Health Syst 2007;1:5.

41 Norris FH, Alegria M. Mental health care for ethnic minority individuals and communities in the aftermath of disasters and mass violence. CNS Spectr 2005;10:132-40.

42 Hyland P, Shevlin M, Fyvie C, et al. Posttraumatic stress disorder and complex posttraumatic stress disorder in DSM-5 and ICD-11: clinical and behavioral correlates. J Trauma Stress 2018;31:174-80.

43 Hyland P, Ceannt R, Daccache F, et al. Are posttraumatic stress disorder (PTSD) and complex-PTSD distinguishable within a treatment-seeking sample of Syrian refugees living in Lebanon? Glob Ment Health 2018;5:e14.

44 Steel Z, Chey T, Silove D, et al. Association of torture and other potentially traumatic events with mental health outcomes among 
populations exposed to mass conflict and displacement: a systematic review and meta-analysis. JAMA 2009;302:537-49.

45 American Psychiatric Association. Diagnostic and statistical manual of mental disorders. Arlington, VA: American Psychiatric Associaton, 2013.

46 American Psychiatric Association. Highlights of changes from DSMIV-TR to DSM-5. Arlington, VA: American Psychiatric Association, 2013.

47 Schnyder U, Müller J, Morina N, et al. A comparison of DSM-5 and DSM-IV diagnostic criteria for posttraumatic stress disorder in traumatized refugees. J Trauma Stress 2015;28:267-74.
48 Danzi BA, La Greca AM. Dsm-Iv, DSM-5, and ICD-11: identifying children with posttraumatic stress disorder after disasters. J Child Psychol Psychiatry 2016;57:1444-52.

49 Wright M, Lin A, O'Connell M. Commentary on black et al., a systematic review: identifying the prevalence rates of psychiatric disorder in Australia's Indigenous populations. Aust N Z J Psychiatry 2015:49:1062-3.

50 AlHW. Australia's Welfare 2017: in brief. Canberra: Australian Institute of Health and Welfare, 2017.

51 Shepherd CCJ, Li J, Zubrick SR. Social gradients in the health of Indigenous Australians. Am J Public Health 2012;102:107-17. 